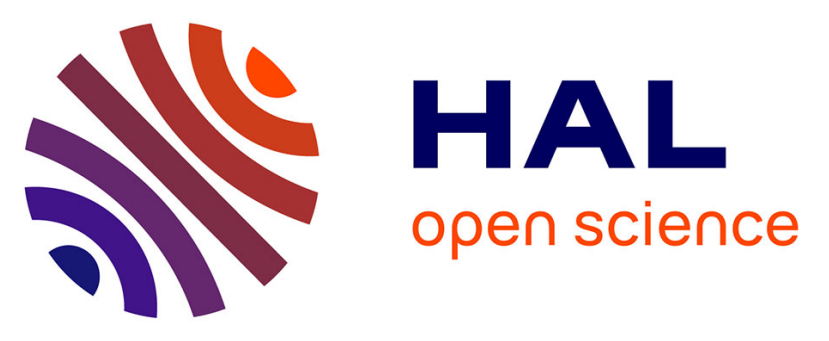

\title{
Presbyopia management with Q-factor modulation without additive monovision: One-year visual and refractive results
}

Fabien Rouimi, Sofiane Ouanezar, Isabelle Goemaere, Anne Charlotte Bayle, Vincent Borderie, Laurent Laroche, Nacim Bouheraoua

\section{To cite this version:}

Fabien Rouimi, Sofiane Ouanezar, Isabelle Goemaere, Anne Charlotte Bayle, Vincent Borderie, et al.. Presbyopia management with Q-factor modulation without additive monovision: One-year visual and refractive results. Journal of Cataract and Refractive Surgery, 2019, 45, pp.1074 - 1083. 10.1016/j.jcrs.2019.02.039 . hal-03487913

\section{HAL Id: hal-03487913 \\ https://hal.science/hal-03487913}

Submitted on 20 Dec 2021

HAL is a multi-disciplinary open access archive for the deposit and dissemination of scientific research documents, whether they are published or not. The documents may come from teaching and research institutions in France or abroad, or from public or private research centers.
L'archive ouverte pluridisciplinaire HAL, est destinée au dépôt et à la diffusion de documents scientifiques de niveau recherche, publiés ou non, émanant des établissements d'enseignement et de recherche français ou étrangers, des laboratoires publics ou privés.

\section{(ㄷ)(1) $\$$}

Distributed under a Creative Commons Attribution - NonCommerciall 4.0 International 
1 Presbyopia management with Q-factor modulation without additive monovision: one-

2 year visual and refractive results

3

4 Fabien Rouimi, M.D ${ }^{1}$, Sofiane Ouanezar, M.D ${ }^{1}$, Isabelle Goemaere, M.S ${ }^{1}$, Anne Charlotte

5 Bayle, M.S ${ }^{1}$, Vincent Borderie, M.D, Ph.D ${ }^{1,2}$, Laurent Laroche, M.D ${ }^{1,2}$, Nacim Bouheraoua

6 M.D, Ph.D ${ }^{1,2}$

7

$8{ }^{1}$ Quinze-Vingts National Ophthalmology Hospital, UPMC - Sorbonne Université, Paris, 9 France.

$10 \quad{ }^{2}$ Institut de la Vision, INSERM UMR S 968, UPMC - Sorbonne Université, Paris, France

Corresponding author: Nacim Bouheraoua, M.D., Ph.D.

Quinze-Vingts National Ophthalmology Hospital. 28, rue de Charenton, 75012 Paris, France.

Running title: Presbylasik by Q-factor modulation

21 Keys words: Cornea; presbyLASIK; presbyopia; Q factor; corneal asphericity; spherical

Financial disclosure: The authors have no conflict of interest to declare. 


\section{Abstract}

Purpose: To analyze refractive results after hyperopic presbyopia surgery by Q-factor modulation without additive monovision.

Setting: Quinze-Vingts National Ophthalmology Hospital, Paris, France.

Design: Prospective non-randomized study.

Methods: We included 90 eyes from 45 hyperopic presbyopic patients not tolerating monovision. The target for the dominant eye (DE) was emmetropy, whereas that for the nondominant eye (NDE) was emmetropy associated with a target Q-factor of -0.8. Postoperative follow-up included assessments of spherical equivalent refraction (SEQ), monocular and binocular corrected (CDVA) and uncorrected (UDVA) distance, binocular corrected (CNVA) and uncorrected (UNVA) near visual acuities. Corneal pachymetry, topography, aberrometry and an analysis of patient satisfaction were performed at the 12-month examination.

Results: Mean age at surgery was $53.8 \pm 4.99$ years. Mean preoperative SEQ was $+2.33 \pm$ 1.16 diopters (D) for the DE and $+2.26 \pm 1.17 \mathrm{D}$ for the NDE. At 12 months, $93 \%$ of patients had a binocular UDVA of Snellen $20 / 20$ and $82 \%$ had a binocular UNVA of Jaeger 2 (Parinaud 3). Mean SEQ at 12 months was $-0.22 \pm 0.35 \mathrm{D}(P<0.0001)$ for the DE and $-0.83 \pm$ $0.50 \mathrm{D}(P<0.0001)$ for the NDE. Two eyes required retreatment. Overall, $87 \%$ of the patients said that they were satisfied and would recommend the intervention.

Conclusion: Q-factor modulation without additive monovision aims to compensate for presbyopia by changing the Q-factor of the NDE to generate a greater depth of field in hyperopic presbyopic patients unable to tolerate monovision. Visual outcome and quality of vision were satisfactory and few patients required additional correction. 


\section{Introduction}

The management of presbyopia has long been a subject of interest to ophthalmologists. As the population ages, this progressive decrease in the ability to focus on nearby objects becomes more prevalent, together with an increasing need for the correction of both near and intermediate vision. Both ophthalmologists and patients are seeking a safe, effective procedure to replace accommodation, to restore a full range of vision. The correction of presbyopia and the restoration of accommodation are therefore considered to be major issues in the field of refractive surgery. The surgical correction of presbyopia is a hot topic in refractive surgery, for which rapid progress has been made over the last few years.

Various approaches for the correction of this disability have been evaluated, including multifocal intraocular lenses, accommodative intraocular lenses, laser-assisted corneal surgery and intracorneal inlays ${ }^{1}$. Laser in situ keratomileusis (LASIK) is the most widely performed corneal refractive procedure worldwide, and recent improvements in our understanding of corneal aberrometry have paved the way for laser-assisted procedures involving changes in corneal asphericity ${ }^{2,3}$. The increase in depth of field obtained in this way could improve intermediate and near vision, to the extent that the patient may no longer be dependent on spectacles $^{4}$. Many multifocal or aspherical laser-assisted corneal surgery techniques have been developed, some uni or bilateral, peripheral, centered or off-center, and they are all grouped together under the umbrella term presbyLASIK. Central multifocal ${ }^{5-10}$ or aspherical ${ }^{11-16}$ presbyLASIK is the technique of choice today, and may be combined with monovision to enable patients to benefit from both techniques. Results have been reported for F-CAT associated with monovision on the non-dominant eye $(\mathrm{NDE})^{12-16}$, but visual results are lacking for isolated aspheric treatment on the NDE in patients unable to tolerate monovision. In this study, we assessed, in hyperopic patients, the visual and refractive outcome of presbyopia surgery based on central presbyopic LASIK with corneal asphericity modulation 
by Q-factor modification of the F-CAT program on the NDE without additive monovision, associated with emmetropy for the dominant eye (DE), focusing, in particular, on postoperative quality of vision.

\section{Materials and Methods}

This prospective non-randomized observational study of consecutive hyperopic patients with presbyopia was performed between February 2012 and November 2015 at the Quinze-Vingts National Ophthalmology Hospital in Paris, France. Informed consent was obtained from each patient before inclusion in the study, in accordance with the Declaration of Helsinki, and the study was approved by the Ethics Committee of the French Society of Ophthalmology (Institutional Review Board 00008855).

Patients with minimum of +1.00 diopters (D) of hyperopic manifest refraction and clinically significant presbyopia were included. The inclusion criteria were as follows: corrected distance visual acuity (CDVA) of Snellen 20/20 or better, demonstrated stable manifest refraction for at least one year, a clear lens, no ocular condition or history of ocular surgery, and a poor tolerance of monovision which was defined by a marked discomfort after wearing a day contact lens with $+1.00 \mathrm{D}$ added to the non-dominant eye. Patients with a high risk of post-LASIK ectasia according to the Ectasia Risk Score System designed by Randleman and colleagues were not included in this series ${ }^{17}$. The other exclusion criteria were systemic chronic disease and corectopia. The minimum required follow-up was fixed at 12 months post-surgery.

Before surgery, all patients underwent a complete ophthalmologic examination, including manifest refraction, cycloplegic refraction, determination of DE in the hole-in-the-card test and the preferential blur test, monovision test with contact lens for a day with +1.00 added to the non-dominant eye, slit-lamp microscopy of the anterior segment, dilated fundus examination, intraocular pressure measurement, corneal topography, pachymetric mapping 
and aberrometry. Monocular and binocular uncorrected distance visual acuity (UDVA),

107 CDVA and binocular uncorrected near visual acuity (UNVA) and corrected near visual acuity 108 (CNVA) were measured in the following conditions. Near vision was recorded as the smallest

109 print the patient could read fluently and comfortably on the Parinaud reading chart at $35 \mathrm{~cm}$

110 with and without correction.

111 Corneal topography was performed with the Orbscan IIz system (Orbscan II, Bausch and

112 Lomb surgical, Rochester, NY). Corneal pachymetry was performed by high-resolution

113 anterior segment optical coherence tomography (AS-OCT) (RTVue, OptoVue, Inc, Fremont,

114 CA, USA). Wavefront aberrometry measurements were obtained with an ITrace aberrometer

115 (Hoya, Tokyo, Japan) on the undilated pupil in scotopic condition without pharmacological

116 dilatation knowing that the study examines corneal wavefront aberrations and that the pupil

117 diameter is not critical. The main outcome measurements were the efficacy, accuracy,

118 stability and safety of the procedure. Patient satisfaction was also assessed at the last follow-

119 up visit. Efficacy was evaluated by measuring binocular UDVA and UNVA. Accuracy was

120 evaluated by comparing the target and achieved spherical equivalent refraction (SEQ) and Q-

121 factor. Pachymetry, central keratometry, and the root mean square (RMS) values of the

122 Zernike corneal spherical aberration coefficient $\left(\mathrm{C}_{4}{ }^{0}\right)$ were also evaluated. Stability was

123 evaluated by analyzing changes in SEQ over the year following surgery. Safety was evaluated

124 by slit-lamp examination, near and distance CDVA for both eyes, and changes in CDVA

125 between the preoperative and postoperative examinations. Patients were asked whether they

126 were satisfied with their visual comfort for everyday activities and whether they would

127 recommend the surgery, 12 months after the intervention (or 12 months after the first

128 procedure in cases of retreatment). All procedures were performed with an IntraLase ${ }^{\mathrm{TM}}$

129 femtosecond laser (Abbott Medical Optics, Santa Ana, USA) and the WaveLight EX500

130 Allegretto Wave ${ }^{\mathrm{TM}}$ Excimer Laser System (Alcon, Fort Worth, TX Inc) in the same dedicated 
131 operating room. All patients underwent a standard LASIK procedure on both eyes on the

132 same day with similar settings, under topical anesthesia with oxybuprocaine $(1.6 \mathrm{mg} / 0.4 \mathrm{ml}$;

133 oxybuprocaine chlorhydrate, Thea, Clermont-Ferrand, France). A 9-mm flap with a target

134 depth of 110 microns was created in each case. The target optical zone was $6.5 \mathrm{~mm}$ in all

135 cases, with a transition zone of $1.0 \mathrm{~mm}$.

136 For the DE, a standard Wavefront Optimized treatment was performed, aiming for emmetropy

137 and distance vision. For the NDE, an aspheric treatment was performed with the F-CAT

138 treatment planning module. The target Q-factor setting was -0.8 for all patients, regardless of

139 the preoperative Q-factor. This treatment aimed to modify mean asphericity by adjusting the

140 number of midperipheral laser pulses. A readjustment of target refraction by myopization was

141 required to compensate for the defocusing induced by Q-factor modification, but without

142 additional myopization (no additive monovision).

143 The postoperative treatment was topical tobramycin and dexamethasone (Tobradex $®$, Alcon

144 Laboratories, Inc.), three times daily for one week and lubricant for one month. Postoperative

145 check-ups were scheduled for one day, one week, one month, and at least 12 months after

146 surgery. Postoperative follow-up included slit-lamp examination, monocular and binocular

147 UDVA and CDVA, binocular UNVA and CNVA measurements. Corneal pachymetry, 148 corneal topography, and aberrometry and an assessment of satisfaction were also performed at 149 the 12-month visit.

$150 \quad$ Safety and efficacy

151 The safety and efficacy indices were assessed. The efficacy index was defined as mean 152 postoperative UDVA divided by mean preoperative CDVA. The safety index was defined as 153 mean postoperative CVDA divided by mean preoperative CDVA. 
157 The results are presented as means and standard deviations for continuous variables and as 158 proportions for discrete variables. We used the D'Agostino-Pearson test to assess the normal 159 distribution of our data and then used parametric statistics. We used $t$-tests to compare 160 continuous data, as appropriate, and $t$-tests for paired data to evaluate the significances of 161 differences in continuous data before and after surgery. We used Spearman's correlation coefficient test to explore the relationships between values. Snellen visual acuities were converted into logarithm of the minimum angle of resolution (logMAR) units for analysis.

164 Corrected $P$ values $<0.05$ were considered statistically significant. Statistical analysis was 165 performed with SPSS for Windows version 20.0 (SPSS, Inc, Chicago, IL).

\section{Results}

167

168

169

170

\section{Preoperative assessment}

We treated 90 eyes in 45 consecutive patients. There were 20 men and 25 women and the mean age of the patients was $53.8 \pm 4.99$ years. Mean preoperative SEQ was $+2.33 \pm 1.16 \mathrm{D}$ for the DE and $+2.26 \pm 1.17 \mathrm{D}$ for the NDE. The mean addition for binocular near vision was $+2.3 \pm 0.48$. There was no significant difference in refraction between the two eyes in any of the patients. Mean minimal pachymetric corneal thickness was $541 \pm 30 \mu \mathrm{m}$ for the DE and $539 \pm 30 \mu \mathrm{m}$ for the NDE. Mean Kmax was $44.3 \pm 1.47 \mathrm{D}$ for the DE and $44.1 \pm 1.45 \mathrm{D}$ for the NDE. The mean corneal Q factor at $6 \mathrm{~mm}$ before surgery was $-0.19 \pm 0.05$ for the NDE and $0.18 \pm 0.04$ for the DE. The RMS values of the Zernike corneal spherical aberration coefficient $\left(\mathrm{C}_{4}{ }^{0}\right)$ on a pupil of $6 \mathrm{~mm}$ in diameter were $0.21 \pm 0.13 \mu \mathrm{m}$ for the DE and $0.20 \pm$ $0.12 \mu \mathrm{m}$ for the NDE. Mean preoperative UDVA was 20/63 (logMAR $0.45 \pm 0.28)$ for the DE and 20/63 (logMAR $0.45 \pm 0.29)$ for the NDE. Mean preoperative CDVA was 20/16 $(\operatorname{logMar}-0.084 \pm 0.076)$ for the DE and 20/16 (logMar $-0.098 \pm 0.076)$ for the NDE. Mean preoperative binocular CNVA was Jaeger 1 (Parinaud 2) $(\operatorname{logMAR} 0.16 \pm 0.046)$. The 
181 readjustment of target refraction by myopization necessary to compensate for the defocusing

182 induced by Q-factor modification was about $-1.3 \pm 0.79 \mathrm{D}$ on average in our study. The

183 results of the preoperative assessments are summarized in Table 1.

\section{Efficacy}

185 Mean binocular UDVA at 12 months after surgery was 20/20 (logMAR $-0.072 \pm 0.07)$. Mean

186 binocular UNVA was Jaeger 2 (Parinaud 3) (logMAR $0.28 \pm 0.14)$. At 12 months of follow187 up, 93\% of patients had a binocular UDVA of Snellen 20/20 or better (figure 1) and 82\% had 188 a binocular UNVA of Jaeger 2 (Parinaud 3) or better, with 51\% achieving a binocular UNVA

189 of Jaeger 1 (Parinaud 2) or better (figure 2). The distributions of binocular and monocular 190 UDVA and binocular UNVA are presented in figures 1 and 2, respectively. The mean 191 efficacy index was 0.809 for the DE.

192 Accuracy

193 At one year, the mean manifest refraction spherical equivalent (SEQ) was $-0.22 \pm 0.35$ and

$194-0.83 \pm 0.5$ for the DE and the NDE, respectively. SEQ differed significantly between the two 195 eyes of each patient after surgery $(P<0.001)$. Accuracy data for DE and NDE SEQ are 196 presented in figures 3 and 4.

197 For keratometry, measured Kmax had significantly changed for both the DE $(44.3 \pm 1.47 \mathrm{D}$ 198 vs. $45.34 \pm 1.29 \mathrm{D}(P<0.0001))$ and for the $\operatorname{NDE}(44.14 \pm 1.45 \mathrm{D}$ vs. $45.47 \mathrm{D} \pm 1.37 \mathrm{D}$ $199(P<0.0001)) 12$ months after surgery. Minimal pachymetric corneal thickness had changed 200 from $541 \pm 30 \mu \mathrm{m}$ to $522 \pm 24 \mu \mathrm{m}(P<0.0001)$ for the DE, and from $539 \pm 30 \mu \mathrm{m}$ to $524 \pm 28$ $201 \mu \mathrm{m}(P<0.0001)$ for the NDE. The results of the one-year assessment are summarized in Table 2021.

203 Corneal asphericity and spherical aberrations

204 The corneal Q factor at $6 \mathrm{~mm}$ before surgery was $-0.19 \pm 0.05$ for the NDE and $-0.18 \pm 0.04$ 205 for the DE. This factor was significantly modified by surgery, to $-0.78 \pm 0.04$ for NDE 
$(P<0.0001)$ and $-0.48 \pm 0.03$ for $\mathrm{DE}(P<0.0001)$ (figure 5). The difference in $\mathrm{Q}$ achieved at

20712 months was significantly greater for the NDE than for the DE $(-0.58 \pm 0.22$ vs. $-0.31 \pm$ $208 \quad 0.17, P<0.0001$ ) (figure 5).

209 Twenty-four of the 45 patients underwent aberrometry at 12 months of follow-up. The RMS 210 values for the Zernike corneal spherical aberration coefficient $\left(\mathrm{C}_{4}{ }^{0}\right)$ for a pupil of $6 \mathrm{~mm}$ in 211 diameter were $0.21 \pm 0.13 \mu \mathrm{m}$ for the DE and $0.20 \pm 0.12 \mu \mathrm{m}$ for the NDE. These values had 212 become negative 12 months after surgery, at $-0.06 \pm 0.17 \mu \mathrm{m}$ and $-0.24 \pm 0.12 \mu \mathrm{m}$, 213 respectively (figure 6). At 12 months the changes in $\mathrm{C}_{4}{ }^{0} \mathrm{RMS}$ values after surgery were 214 significantly greater for the NDE than for the DE $(-0.43 \pm 0.17$ vs. $-0.26 \pm 0.15 \mu \mathrm{m}$, 215 respectively; $P=0.002$ ) (figure 6).

$216 \quad$ Stability

217 SEQ refraction stability is presented in figure 7. The SEQ of the DE was stable over the 12 218 months following surgery, with a non-significant mean change from $-0.3 \pm 0.3 \mathrm{D}$ at 1 month 219 to $-0.22 \pm 0.35 \mathrm{D}(P=0.1)$ at 1 year, and a progressive shift in myopia toward emmetropia for 220 the NDE was observed, with a significant mean change from $-1.07 \pm 0.45 \mathrm{D}$ at 1 month to $2210.83 \pm 0.5 \mathrm{D}(P=0.04)$ at 1 year.

\section{$222 \quad$ Safety and complications}

223 Mean CDVA for the DE was $\log$ MAR $-0.084 \pm 0.076$ (Snellen 20/16) before and $\log$ MAR $0.092 \pm 0.06$ (Snellen 20/16) after surgery. For the NDE, mean CDVA was logMAR $-0.098 \pm$ 0.075 (Snellen 20/16) before and $\log$ MAR $-0.091 \pm 0.067$ (Snellen 20/16) after surgery. For each treatment, the monocular loss of CDVA was minimal: three patients (7\%) lost one line 227 of Snellen CDVA for the DE and 10 patients (22\%) lost one line of Snellen CDVA for the 228 NDE (Figure 8).

229 All of the patients attained a CDVA of at least logMAR $0(20 / 20$ Snellen lines) for the DE 230 and the NDE; $91 \%$ of UDVA values for the DE were within one line of Snellen CDVA and 
$94 \%$ of the binocular UDVA values were within one line of Snellen CDVA. The difference

232 between postoperative UDVA and preoperative CDVA is presented in figure 9. The safety 233 indices were 0.929 for the NDE and 1.095 for the DE. No intraoperative or postoperative 234 complications occurred.

235 Two eyes required retreatment. The first patient underwent retreatment four months after 236 initial surgery, on an overcorrected DE, to improve UDVA. The DE SEQ improved from 2370.75 to $0 \mathrm{D}$ after this intervention. Binocular UDVA improved from 20/80 to 20/20 after 238 surgery (12-month visit). The second patient underwent retreatment six months after initial 239 surgery, on the NDE, to improve UNVA by an additional +1D because the postoperative 240 NDE SEQ was 0 D. Binocular UDVA and UNVA were 20/16 and Jaeger 3 (Parinaud 4), 241 respectively, before retreatment. Six months after retreatment, binocular UNVA increased to 242 Jaeger 1 (Parinaud 2), and there was no change in binocular UDVA.

\section{$243 \quad \underline{\text { Satisfaction }}$}

244 Twelve months after the initial intervention, 39 patients (87\%) declared themselves satisfied 245 with their visual comfort for everyday activities and said that they would recommend this 246 surgery. The patients declaring themselves not satisfied included the two cases requiring 247 retreatment. At the last follow-up visit, two patients (4\%) still required glasses, with a 248 minimal correction of about $-0.50 \mathrm{D}$ for the non-dominant eye, to improve distance vision for 249 activities requiring sustained concentration. Three patients $(7 \%)$ needed glasses for near 250 vision, with an additional correction of about +1 D. Two patients reported halos, particularly 251 when driving at night. None of the patients spontaneously complained of eye dryness.

\section{Discussion}

253 The technique used here was expected to combine the benefits of classic hyperopic Lasik on 254 the DE to improve distance vision and to induce myopic defocus and a negative spherical 255 aberration value in the NDE, to increase depth of field and improve near vision. This method 
can also be combined with monovision to reduce the degree of myopia and increase 257 tolerability ${ }^{18,19}$. A number of concerns, including optical and visual distortion, and a decline 258 in uncorrected distance vision ${ }^{11}$, have prevented the widespread acceptance of these 259 procedures. Hyperopic presbyopic individuals seem to be good candidates for these 260 procedures, as standard Excimer ablation profiles already induce corneal prolatization ${ }^{20,}{ }^{21}$. 261 The achievement of a more negative Q-factor value may increase corneal asphericity, 262 increasing the negative aberration and potentially improving depth of field ${ }^{22,23}$. However, this change in asphericity involves a hyperopic defocus for peripheral incoming light rays. This must be corrected when setting the laser parameters, by aiming for a negative refractive target, so as to keep the defocus Zernike coefficient unchanged.

266 By comparison with classic monovision treatment, the change in asphericity induces a certain 267 degree of multifocality in the NDE, potentially combining an improvement of near vision 268 with a limited impairment of binocular distance vision. Indeed, a loss of visual quality for near or distance vision has been reported in service series of classic monovision cases ${ }^{24}$.

270 The LASIK correction of presbyopia with different software suites for treatment planning 271 software has frequently been evaluated. Most of these techniques, referred to collectively as 272 presbyLASIK, involve monocular or binocular asphericity changes to improve the depth of 273 field. For our study, we performed on the dominant eye a classical hypermetropic treatment 274 leading to emmetropisation for far vision, and for the non-dominant eye, an aspheric 275 treatment with a target Q factor of -0.8 and hypermetropic induced defocus readjustment with 276 no monovision added. 93\% of the patients achieved a binocular UDVA of Snellen 20/20 or 277 better and 82\% achieved a binocular UNVA of Jaeger 2 (Parinaud 3) or better, with 51\% 278 achieving a binocular UNVA of Jaeger 1 (Parinaud 2). Good visual acuity was obtained for 279 distance vision, together with a close vision sufficient for everyday activities, such as reading 280 the newspaper (Jaeger 2/Parinaud 3). However, for activities requiring some accuracy, 
additional optical correction may be required for some patients. This is probably due to the

282 absence of programmed additive monovision in the patients studied ${ }^{15}$.

283 These findings are consistent with those for a published series on the Wavelight Allegretto 284 EX500 F-CAT program. In a recent series reported by Leray and colleagues ${ }^{12}$, 93\% of 285 patients achieved a binocular UDVA of $20 / 20$ and $71 \%$ achieved a binocular UNVA of 286 Parinaud 2 or better three months after surgery. The laser parameters were different from 287 those used here, with a refractive target for the NDE of $-0.75 \mathrm{D}$ and a target Q factor of $-0.8 \mathrm{D}$ 288 to induce monovision in addition to multifocality. Near vision was better in this previous study, probably due to the very slight monovision added. In another series reported by Ho 290 Wang Yin and colleagues ${ }^{14}, 100 \%$ at one year of follow-up had a binocular UDVA of 20/20 291 or better and $70 \%$ had a binocular UNVA of Jaeger 2 (Parinaud 3) or better. The refractive 292 target and the target Q factor for the NDE were set at $-0.50 \mathrm{D}$ and between -0.6 and -0.8 . In another series described by Courtin and colleagues ${ }^{13}, 91 \%$ of patients had a binocular UDVA of 20/20 or better, $89 \%$ had a binocular UNVA of Jaeger 2 (Parinaud 3) or better and $83 \%$ had a binocular UNVA of Jaeger 1 (Parinaud 2) or better at 6 months, with a target $\Delta \mathrm{Q}$ for the NDE of -0.6 to -0.7 (corresponding to a postoperative Q-factor of about 0.8 to 0.9 ) and a 297 variable refractive target for the NDE depending on the addition to near vision required for reading. The added monovision induced better near visual acuity for activities requiring 299 precision (Jaeger 1/Parinaud 2) than was achieved in our study. The setting of the target Q 300 value is a matter of debate ${ }^{19}$ in the absence of a consensus, but considering the natural 301 asphericity of the cornea, we set a target $\mathrm{Q}$ value of -0.8 , which seems to be widely used for 302 presbyopia correction in hyperopic patients and is typical of other published studies on the Q 303 factor. However, unlike these other studies, we did not target postoperative myopia in 304 addition to defocus compensation, but nevertheless achieved to a greater myopisation on the 305 dominant eye $(-0.83$ D) compared to the dominated eye $(-0.22 \mathrm{D})$. Knowing that the 
measurement of the spherical equivalent is made on the central $3 \mathrm{~mm}$ by the

307 autorefractometer, it can be deduced that performing a Q-factor treatment with hypermetropic defocus readjustment induces a slight central myopization responsible for a mini-monovision, which contributes in addition to the NDE induced multifocality to improving near-vision. The procedure resulted in good close visual acuity for activities of daily living, but with less accuracy. Gatinel and colleagues determined a theorical target of change in the $\mathrm{Q}$ factor $(\Delta \mathrm{Q})$, required to achieved a corneal spherical aberration variation $\mathrm{C}_{4}{ }^{0}$ of $-0.40 \mu \mathrm{m}$ for a pupil size of $6 \mathrm{~mm}:-0.60$ to $-0.70^{3}$. If we consider the mean Q factor in the population to be about 0.20 , then we need to target a postoperative $\mathrm{Q}$ factor of between -0.8 and -0.9 . The choice of this change in spherical aberration $\left(\Delta \mathrm{C}_{4}{ }^{0}:-0.40 \mu \mathrm{m}\right)$ is based on clinical practice, in which a 316 larger negative change has been found not to increase depth of focus but to decrease the 317 quality of vision ${ }^{25}$. We set the target $\mathrm{Q}$ factor to -0.8 for all patients and achieved a $\Delta \mathrm{Q}$ close to the target value in the NDE $(-0.58 \pm 0.22$ vs. -0.60 to -0.70$)$ and similar results for $\Delta \mathrm{C}_{4}{ }^{0}(-$ $0.43 \pm 0.17$ vs. $-0.40 \mu \mathrm{m})$. As expected with the classic hyperopic LASIK procedure ${ }^{21}$ on the $\mathrm{DE}$, corneal prolateness increased significantly ( $\Delta \mathrm{Q}$ of $-0.31 \pm 0.17)$. One of the limitations of 321 this study is that only 24 of the 45 patients were able to benefit from wavefront aberrometry 322 measurements because of the unavailability of the aberrometer during part of the follow-up.

323 A progressive shift in myopia toward emmetropia was observed for the SEQ of the NDE, 324 which displayed a mean change from $-1.07 \mathrm{D}$ at 1 month to $-0.83 \mathrm{D}(p=0.04)$ at one year 325 whereas DE SEQ refraction seemed to remain stable over this period $(p=0.1)$. A similar 326 pattern can be observed in the series published by Ho Wang Yin and colleagues, in which 327 NDE SEQ changed from $-1.3 \pm 1.0 \mathrm{D}$ at 1 month after surgery to $-0.7 \pm 0.7 \mathrm{D}$ at 1 year after 328 surgery $^{14}$ and in the series published by Courtin and colleagues, in which SEQ changed from $3291.40 \mathrm{D}$ at 1 month to $-1.07 \mathrm{D}$ at 6 months after surgery ${ }^{13}$. The effectiveness of this procedure 330 probably decreases over time, probably due to the natural regression of hypermetropic LASIK 
associated with a gradual loss of accommodative power. The long-term regression of classic

332 hyperopic LASIK refractive correction was revealed by two studies $^{26,27}$, but longer term 333 studies are required to evaluate the long-term stability of this surgical technique for 334 modulating Q factor.

335 No surgical complications were reported in our series and two patients required retreatment $336(5 \%)$. Courtin and colleagues reported a retreatment rate of $10.7 \%^{13}$ and Ho Wang Yin and 337 colleagues reported a retreatment rate of $23 \%{ }^{14}$. However, the indication for retreatment 338 differs considerably between surgeons and is not really comparable between studies. Also, we 339 can note in our study that the loss rate of one line of CDVA for the NDE (22\%) is much 340 higher than for the DE (7\%). This is explained by the fact that the NDE present, as expected, 341 a corneal asphericity much more marked compared to the DE postoperatively. This corneal 342 asphericity degrades the quality of vision which cannot be compensated by glasses which 343 explains this difference of CDVA between the 2 eyes.

344 In our series, subjective satisfaction with visual comfort for everyday activities was good at 345 the last follow-up visit; $87 \%$ of our patients were satisfied and would recommend this 346 operation. However, satisfaction is highly subjective and depends on the personal needs of the 347 patient concerned. Some patients will be satisfied with an imperfect near vision and will not 348 need glasses, whereas others will be more demanding and will not be able to read without 349 glasses. We also report a good rate of spectacle independence, with $89 \%$ of our patients no 350 longer requiring glasses for any distance.

351 Several Excimer laser platforms have been evaluated for the treatment of both hyperopia and 352 presbyopia, with good results $5,8,11,28$. Using the Carl Zeiss Meditec MEL80 platform, 353 Reinstein and colleagues obtained similar efficacy results, with $81 \%$ of patients achieving a 354 binocular UNVA of Jaeger 2 and 95\% achieving a binocular UDVA of 20/20 one year after 355 surgery $^{11}$. Similarly, Supracor modulates corneal asphericity simultaneously in both eyes. In 
recent studies, visual outcome and global satisfaction with this technique were similar to our results, with retreatment rates ranging from $13 \%$ to $22 \%{ }^{5,28}$.

358 Other surgical approaches for presbyopic compensation have been studied. Several studies 359 reported satisfactory efficacy and safety results for corneal inlays for the treatment of 360 presbyopia in emmetropic or previously LASIK-treated patients ${ }^{29-40}$. There are still concerns 361 about the risks of infection, stromal fibrosis or melting after implantation ${ }^{41}$.

362 Finally, another widespread alternative for correcting both sphero-cylindrical ametropia and 363 presbyopia is intraocular lens implantation. Multifocal intraocular lenses have been widely

364 studied and shown to be effective, with patients frequently no longer requiring spectacles for 365 intermediate vision ${ }^{42}$. However, intraocular implantation is a more invasive procedure, raising 366 questions not only about the risk of infection, but also about that of retreatment in cases of 367 poor visual outcome ${ }^{43}$.

368 We chose to focus on hyperopic presbyopic patients unable to tolerate monovision. Although 369 we did not therefore increase myopization beyond the readjustment of target refraction to 370 compensate for the defocus induced by Q-factor modification, this treatment induces a slight 371 central myopization responsible for a mini-monovision. The beneficial effects for near vision 372 would therefore be expected to fade more rapidly with aging and the progressive loss of accommodation than in patients with associated monovision, but our results for distance and

374 near visual acuities were nevertheless good, with low rates of retreatment and high levels of 375 satisfaction. In conclusion, the treatment of both hyperopia and presbyopia with a Wavefront 376 Optimized ablation program on the DE and the Wavelight Allegretto F-CAT program on the 377 NDE, without additive monovision, seems to be a safe and efficient technique for achieving 378 spectacle independence. 
What was known?

- Q-factor modulation, including increased negativity of the $\mathrm{Q}$ factor (hyperprolateness), improves depth of focus, which is useful for near vision.

- Presbyopia management with Q-factor modulation (F-CAT) with moderate additive monovision (around 0.50-1.0 D) provides good results for distance and near vision, with high rates of spectacle independence for presbyopic hyperopic patients.

388 What does this paper add?

- We evaluated Q-factor modulation (F-CAT) without additive monovision.

- Q-factor modulation (F-CAT) without additive monovision may be used in hyperopic presbyopic patients who do not tolerate monovision. 


\section{Bibliography}

1. Waring GO, Berry DE. Advances in the surgical correction of presbyopia. Int Ophthalmol Clin 2013;53:129-52.

2. Calossi A. Corneal asphericity and spherical aberration. J Refract Surg 2007;23:505-14.

3. Gatinel D, Azar DT, Dumas L, Malet J. Effect of anterior corneal surface asphericity modification on fourth-order zernike spherical aberrations. J Refract Surg 2014;30:708-15.

4. Charman WN. Ablation design in relation to spatial frequency, depth-of-focus, and age. J Refract Surg 2004;20:542-549.

5. Ryan A, O'Keefe M. Corneal approach to hyperopic presbyopia treatment: six-month outcomes of a new multifocal excimer laser in situ keratomileusis procedure. $\mathrm{J}$ Cataract Refract Surg 2013;39:1226-33.

6. Baudu P, Penin F, Arba Mosquera S. Uncorrected binocular performance after biaspheric ablation profile for presbyopic corneal treatment using AMARIS with the PresbyMAX module. Am J Ophthalmol 2013;155:636-47.

7. Garcia-Gonzalez M, Teus MA. Uncorrected binocular performance after biaspheric ablation profile (PresbyMAX) for presbyopic corneal treatment. Am J Ophthalmol $2013 ; 156: 847-8$.

8. Uthoff D, Pölzl M, Hepper D, Holland D. A new method of cornea modulation with excimer laser for simultaneous correction of presbyopia and ametropia. Graefes Arch Clin Exp Ophthalmol Albrecht Von Graefes Arch Klin Exp Ophthalmol 2012;250:1649-61.

9. Jackson WB, Tuan K-MA, Mintsioulis G. Aspheric wavefront-guided LASIK to treat hyperopic presbyopia: 12-month results with the VISX platform. J Refract Surg 2011;27:51929.

10. Jung SW, Kim MJ, Park SH, Joo CK. Multifocal corneal ablation for hyperopic presbyopes. J Refract Surg 2008;24:903-10. 
11. Reinstein DZ, Couch DG, Archer TJ. LASIK for hyperopic astigmatism and presbyopia

421 using micro-monovision with the Carl Zeiss Meditec MEL80 platform. J Refract Surg 2009;25:37-58.

12. Leray B, Cassagne M, Soler V, et al. Relationship between induced spherical aberration

424 and depth of focus after hyperopic LASIK in presbyopic patients. Ophthalmology $425 \quad 2015 ; 122: 233-43$.

426 13. Courtin R, Saad A, Grise-Dulac A, Guilbert E, Gatinel D. Changes to corneal aberrations and vision after monovision in patients with hyperopia after using a customized aspheric ablation profile to increase corneal asphericity (Q-factor). J Refract Surg 2016;32:734-41.

14. Wang Yin GH, McAlinden C, Pieri E, Giulardi C, Holweck G, Hoffart L. Surgical 430 treatment of presbyopia with central presbyopic keratomileusis: One-year results. J Cataract 431 Refract Surg 2016;42:1415-23.

432 15. Alarcón A, Anera RG, Villa C, Jiménez del Barco L, Gutierrez R. Visual quality after 433 monovision correction by laser in situ keratomileusis in presbyopic patients. J Cataract 434 Refract Surg 2011;37:1629-35.

435 16. Gordon M. Presbyopia corrections with the WaveLight ALLEGRETTO: 3-month results. 436 J Refract Surg 2010;26:824-826.

437 17. Randleman JB, Trattler WB, Stulting RD. Validation of the Ectasia Risk Score System for 438 preoperative laser in situ keratomileusis screening. Am J Ophthalmol 2008;145:813-8.

439 18. Zheleznyak L, Sabesan R, Oh J-S, MacRae S, Yoon G. Modified monovision with 440 spherical aberration to improve presbyopic through-focus visual performance. Invest 441 Ophthalmol Vis Sci 2013;54:3157-65.

442 19. Villegas EA, Alcón E, Mirabet S, Yago I, Marín JM, Artal P. Extended depth of focus 443 with induced spherical aberration in light-adjustable intraocular lenses. Am J Ophthalmol $444 \quad 2014 ; 157: 142-9$. 
20. Bottos KM, Leite MT, Aventura-Isidro M, et al. Corneal asphericity and spherical 446 aberration after refractive surgery. J Cataract Refract Surg 2011;37:1109-15.

447 21. Llorente L, Barbero S, Merayo J, Marcos S. Total and corneal optical aberrations induced 448 by laser in situ keratomileusis for hyperopia. J Refract Surg 2004;20:203-16.

449 22. Benito A, Redondo M, Artal P. Laser in situ keratomileusis disrupts the aberration 450 compensation mechanism of the human eye. Am J Ophthalmol 2009;147:424-431.

451 23. Cantú R, Rosales MA, Tepichín E, Curioca A, Montes V, Ramirez-Zavaleta JG. Objective 452 quality of vision in presbyopic and non-presbyopic patients after pseudoaccommodative 453 advanced surface ablation. J Refract Surg 2005;21:603-605.

24. Soler Tomás JR, Fuentes-Páez G, Burillo S. Symmetrical versus asymmetrical 455 PresbyLASIK: results after 18 months and patient satisfaction. Cornea 2015;34:651-7.

456 25. Amigo A, Bonaque S, López-Gil N, Thibos L. Simulated effect of corneal asphericity 457 increase (Q-factor) as a refractive therapy for presbyopia. J Refract Surg 2012;28:413-8.

458 26. Jaycock PD, O'Brart DPS, Rajan MS, Marshall J. 5-year follow-up of LASIK for 459 hyperopia. Ophthalmology 2005;112:191-9.

460 27. Esquenazi S. Five-year follow-up of laser in situ keratomileusis for hyperopia using the 461 Technolas Keracor 117C excimer laser. J Refract Surg 2004;20:356-63.

462 28. Saib N, Abrieu-Lacaille M, Berguiga M, Rambaud C, Froussart-Maille F, Rigal-Sastourne 463 J-C. Central PresbyLASIK for hyperopia and presbyopia using micro-monovision with the 464 Technolas 217P Platform and SUPRACOR Algorithm. J Refract Surg 2015;31:540-6.

465 29. Beer SMC, Santos R, Nakano EM, et al. One-year clinical outcomes of a corneal inlay for 466 presbyopia. Cornea 2017;36:816-20.

467 30. Limnopoulou AN, Bouzoukis DI, Kymionis GD, et al. Visual outcomes and safety of a 468 refractive corneal inlay for presbyopia using femtosecond laser. J Refract Surg 2013;29:12-8. 
31. Moshirfar M, Bean AE, Albarracin JC, Rebenitsch RL, Wallace RT, Birdsong OC.

470 Retrospective comparison of visual outcomes after KAMRA corneal inlay implantation with 471 simultaneous PRK or LASIK. J Refract Surg 2018;34:310-5.

472 32. Vukich JA, Durrie DS, Pepose JS, Thompson V, van de Pol C, Lin L. Evaluation of the 473 small-aperture intracorneal inlay: three-year results from the cohort of the US Food and Drug 474 Administration clinical trial. J Cataract Refract Surg 2018;44:541-56.

475 33. Dexl AK, Jell G, Strohmaier C, et al. Long-term outcomes after monocular corneal inlay 476 implantation for the surgical compensation of presbyopia. J Cataract Refract Surg $477 \quad 2015 ; 41: 566-75$.

34. Tomita M, Kanamori T, Waring GO, et al. Simultaneous corneal inlay implantation and laser in situ keratomileusis for presbyopia in patients with hyperopia, myopia, or emmetropia: 480 six-month results. J Cataract Refract Surg 2012;38:495-506. 35. Tomita M, Waring GO. One-year results of simultaneous laser in situ keratomileusis and small-aperture corneal inlay implantation for hyperopic presbyopia: comparison by age. $\mathbf{J}$ Cataract Refract Surg 2015;41:152-61.

36. Tomita M, Kanamori T, Waring GO, Nakamura T, Yukawa S. Small-aperture corneal inlay implantation to treat presbyopia after laser in situ keratomileusis. J Cataract Refract Surg 2013;39:898-905.

37. Yılmaz OF, Alagöz N, Pekel G, et al. Intracorneal inlay to correct presbyopia: long-term results. J Cataract Refract Surg 2011;37:1275-81.

38. Seyeddain O, Bachernegg A, Riha $\mathrm{W}$, et al. Femtosecond laser-assisted small-aperture 490 corneal inlay implantation for corneal compensation of presbyopia: two-year follow-up. J 491 Cataract Refract Surg 2013;39:234-41.

492 39. Seyeddain O, Grabner G, Dexl AK. Binocular distance visual acuity does not decrease 493 with the Kamra intra-corneal inlay. J Cataract Refract Surg 2012;38:2062. 
494 40. Dexl AK, Seyeddain O, Riha W, et al. Reading performance and patient satisfaction after 495 corneal inlay implantation for presbyopia correction: two-year follow-up. J Cataract Refract 496 Surg 2012;38:1808-16.

497 41. Duignan ES, Farrell S, Treacy MP, et al. Corneal inlay implantation complicated by 498 infectious keratitis. Br J Ophthalmol 2016;100:269-73.

499 42. Pepose JS, Qazi MA, Chu R, Stahl J. A prospective randomized clinical evaluation of 3 500 presbyopia-correcting intraocular lenses after cataract extraction. Am J Ophthalmol $501 \quad 2014 ; 158: 436-446$.

502 43. Jabbarvand M, Hashemian H, Khodaparast M, Jouhari M, Tabatabaei A, Rezaei S. 503 Endophthalmitis occurring after cataract surgery: outcomes of more than 480000 cataract 504 surgeries, epidemiologic features, and risk factors. Ophthalmology 2016;123:295-301. 


\section{Figure legends}

Figure 1: Cumulative histogram of Snellen UDVA values before and one year after bilateral hyperopic LASIK. The graph presents visual outcomes for: A: non-dominant eyes undergoing surgery with an aspherical ablation profile; B: dominant eyes corrected for distance vision; C:

538 binocular vision. 93\% of patients achieved a binocular UDVA of Snellen 20/20 or better one

539 year after surgery. VA: visual acuity; UDVA: uncorrected distance visual acuity

540 Figure 2: Cumulative histogram of Jaeger binocular UNVA before and one year after 541 bilateral hyperopic LASIK. The graph presents visual outcomes for binocular vision: $82 \%$ 542 achieved a binocular UNVA of Jaeger 2 or better one year after surgery.

543 VA: visual acuity; UNVA: uncorrected near visual acuity

544 Figure 3: Scatterplots of attempted against achieved SEQ refraction one year after bilateral 545 hyperopic LASIK for: A: non-dominant eyes; B: dominant eyes. The coefficients of 546 determination are displayed. SEQ: spherical equivalent; $D$ : diopters

547 Figure 4: Accuracy of SEQ with respect to the target for: A: non-dominant eyes; B: dominant 548 eyes. For $87 \%$ of the dominant eyes, SEQ was within $0.50 \mathrm{D}$ of the target value. SEQ: 549 spherical equivalent; D: diopters

550 Figure 5: A: Corneal asphericity values (corneal Q factor) at a pupil size of $6 \mathrm{~mm}$, before and 55112 months after surgery, for the NDE and the DE. The NDE corneal Q factor changed from $5520.19 \pm 0.12$ before surgery to $-0.77 \pm 0.1612$ months after surgery. The DE corneal Q factor 553 changed from $-0.18 \pm 0.11$ before surgery to $-0.49 \pm 0.13$ at 12 months after surgery. B: 554 Change in corneal asphericity values ( $\Delta \mathrm{Q}$ factor for a pupil size of $6 \mathrm{~mm}$ ) from the 555 presurgical value to the value 12 months after surgery for the NDE and the DE. Twelve 556 months after surgery, the change in Q achieved at 12 months was significantly greater for the 557 NDE than for the DE $(-0.58 \pm 0.22$ vs. $-0.31 \pm 0.17, P<0.0001)$. M12: 12 months after 558 surgery; D: diopters; SD: standard deviation; NDE: non-dominant eye; DE: dominant eye 
559 Figure 6: A: Zernike corneal spherical aberration coefficient $\left(\mathrm{C}_{4}{ }^{0}\right)$ at a pupil size of $6 \mathrm{~mm}$ 560 before and 12 months after surgery, for the NDE and the DE. The NDE $\mathrm{C}_{4}{ }^{0}$ changed from 0.2 $561 \pm 0.12 \mu \mathrm{m}$ before surgery to $-0.24 \pm 0.12 \mu \mathrm{m} 12$ months after surgery. The $\mathrm{DE} \mathrm{C}_{4}{ }^{0}$ changed 562 from $0.21 \pm 0.13 \mu \mathrm{m}$ before surgery to $-0.06 \pm 0.17 \mu \mathrm{m} 12$ months after surgery. B: Change in 563 Zernike corneal spherical aberration coefficient $\left(\Delta \mathrm{C}_{4}{ }^{0}\right)$ from the value before surgery to that 56412 months after surgery, for the NDE and the DE. Twelve months after surgery, the change in $565 \mathrm{C}_{4}{ }^{0} \mathrm{RMS}$ value was significantly greater for the NDE than for the DE $(-0.43 \pm 0.17$ vs. -0.26 $566 \pm 0.15 \mu \mathrm{m}$, respectively; $P=0.002)$. M12: 12 months after surgery; SD: standard deviation; RMS: root mean square; NDE: non-dominant eye; DE: dominant eye

568 Figure 7: Stability of spherical equivalent refraction over the 12 months after surgery for: A: 569 the dominant eye. B: the non-dominant eye. The DE SEQ was stable over the 12 months of 570 postoperative follow-up, with a non-significant mean change from $-0.3 \pm 0.3 \mathrm{D}$ at 1 month to $-0.22 \pm 0.35 \mathrm{D}(P=0.1)$ at 1 year. A progressive shift in myopia toward emmetropia was observed for the NDE SEQ, with a significant mean change from $-1.07 \pm 0.45 \mathrm{D}$ at 1 month to $-0.83 \pm 0.5 \mathrm{D}(P=0.04)$ at 1 year.

574 D: diopters; SD: standard deviation; NDE: non-dominant eye; DE: dominant eye; SEQ: 575 spherical equivalent.

576 Figure 8: Change in Snellen lines of CDVA for: A: the non-dominant eye; B: the dominant 577 eye.

578 No loss of Snellen lines of CDVA was observed for $78 \%$ of non-dominant eyes and $93 \%$ of 579 dominant eyes. CDVA: corrected distance visual acuity

580 Figure 9: Difference between one-year postoperative UDVA and preoperative CDVA for: A: 581 the dominant eye; B: the non-dominant eye; C: both eyes. Postoperative UDVA was within 582 one Snellen line of preoperative CDVA for $91 \%$ of DE, and for $94 \%$ of both eyes. UDVA: 
583 uncorrected distance visual acuity; CDVA: corrected distance visual acuity; NDE: non-

584 dominant eye; DE: dominant eye

585

586

587

588

589 


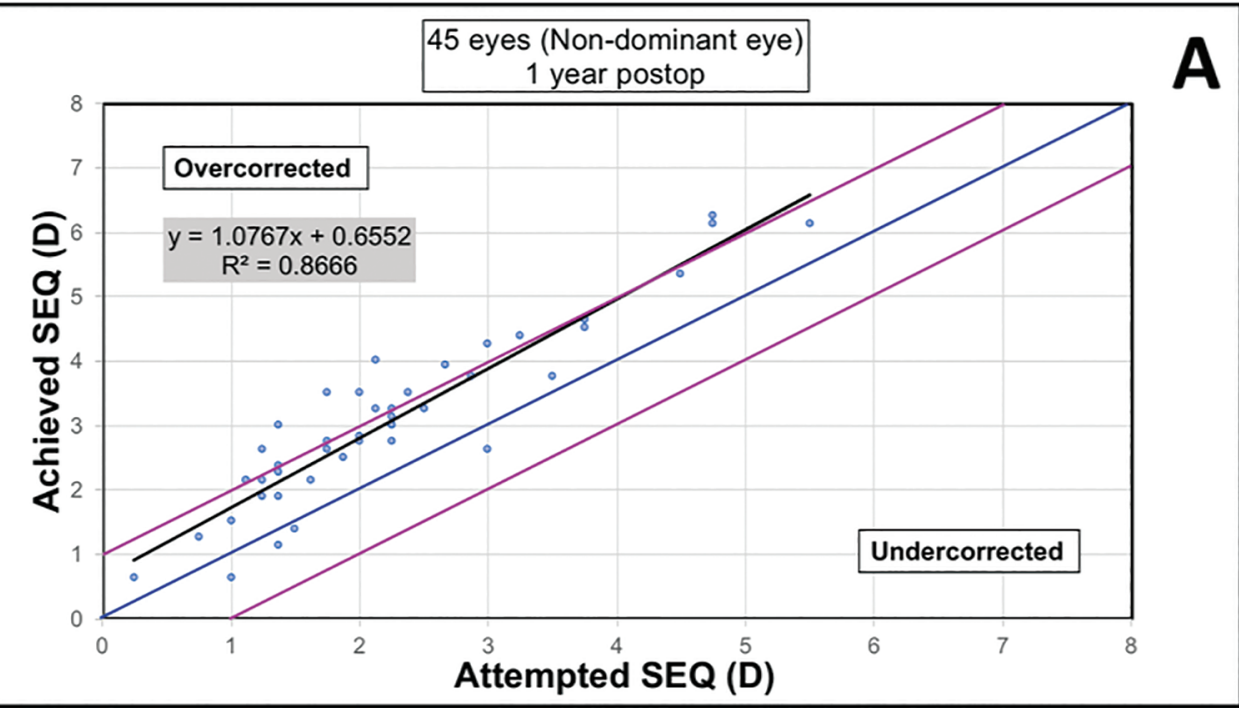

45 eyes (Dominant eye)

1 year postop

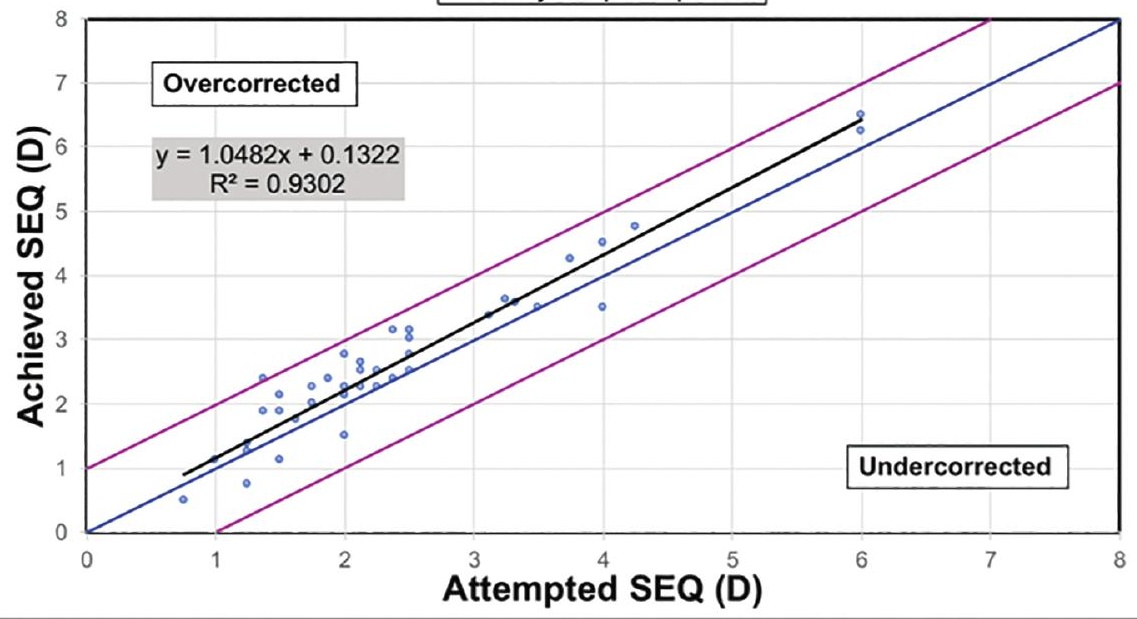



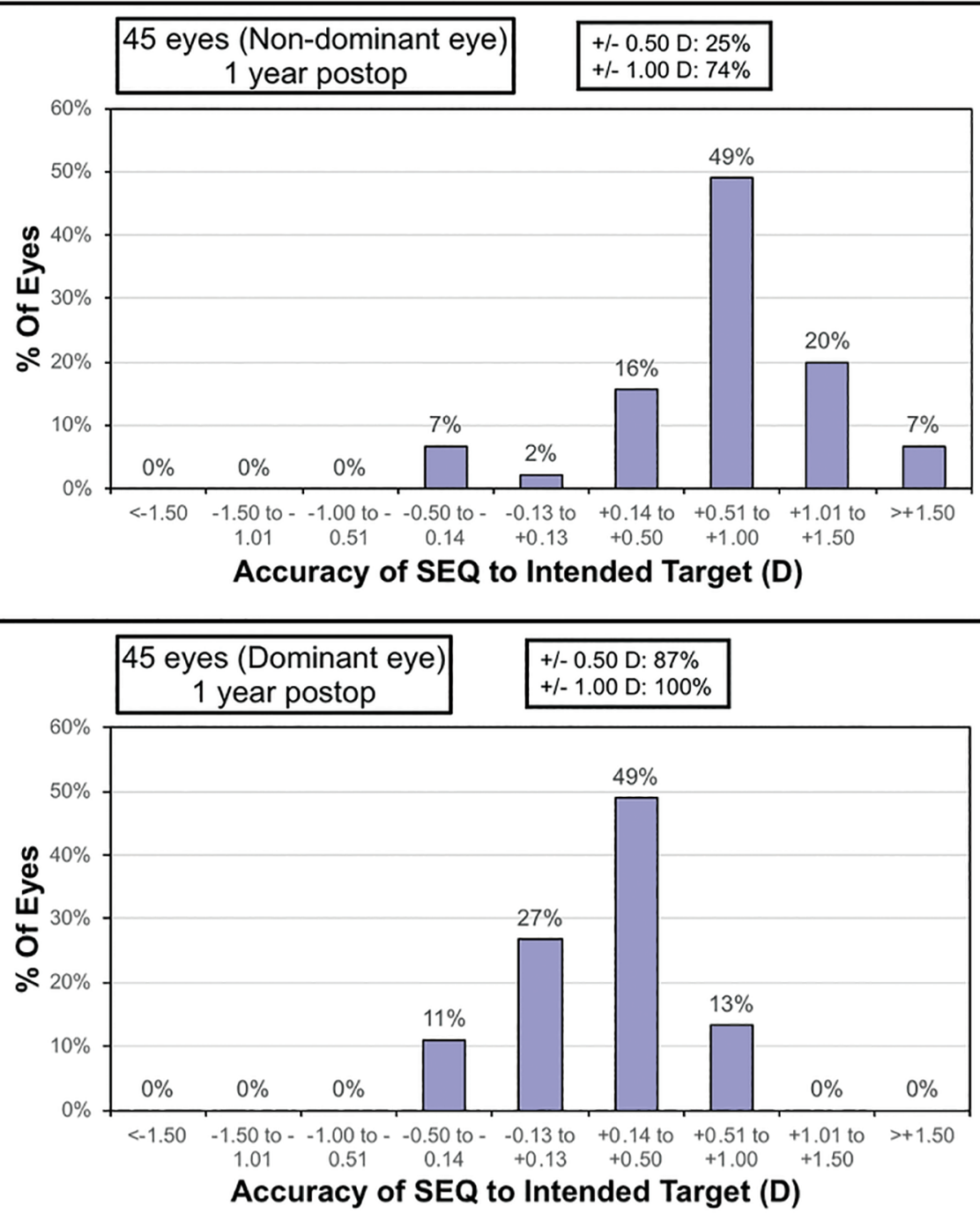
Corneal asphericity values (Q)

Preoperative

Postoperative

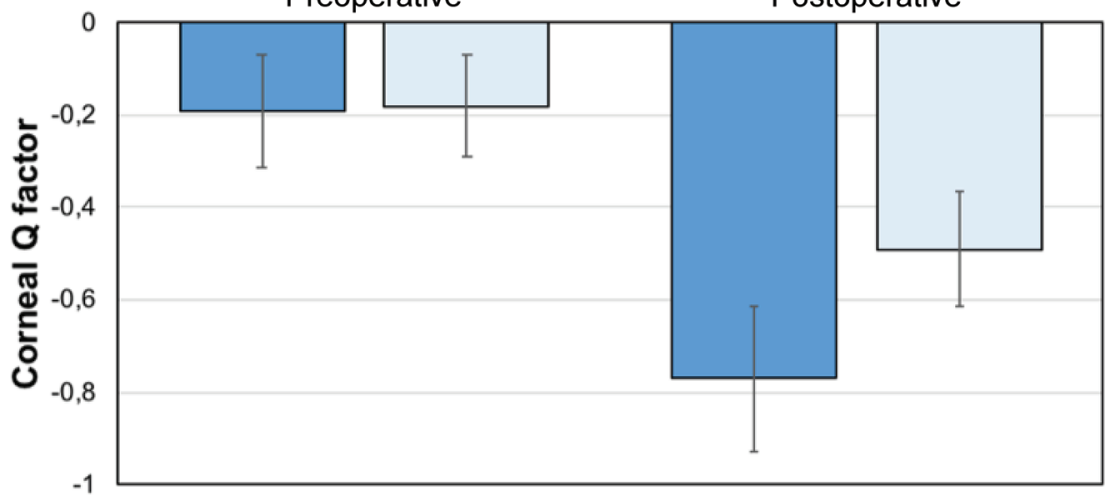

口NDE Corneal Q@6.0mm aDE Corneal Q@6.0mm

Change in corneal asphericity values M12-preop( $\Delta Q)$

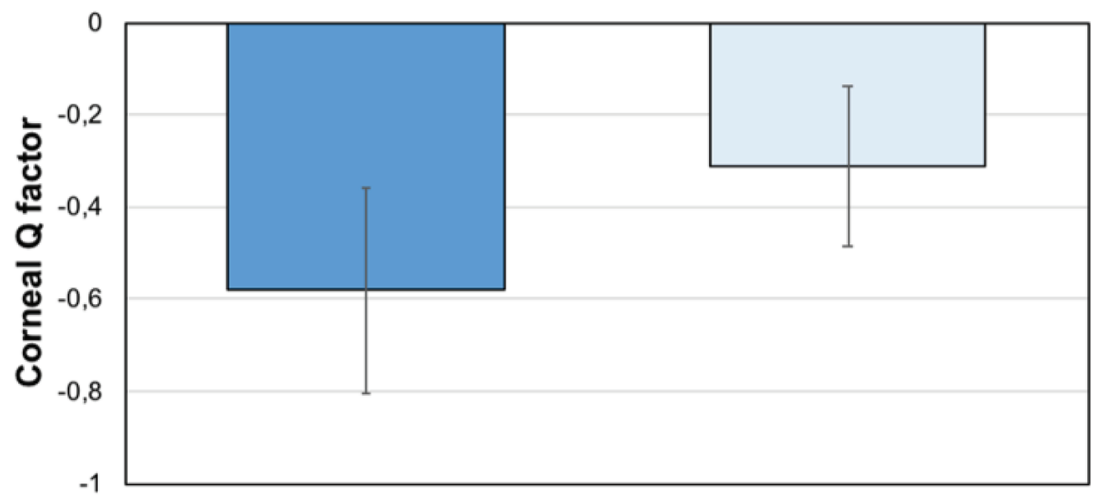

口NDE Corneal $\Delta \mathrm{Q} @ 6.0 \mathrm{~mm} \quad \square \mathrm{DE}$ Corneal $\Delta \mathrm{Q} @ 6.0 \mathrm{~mm}$ 


\section{Zernike corneal spherical aberration coefficient (C40)}

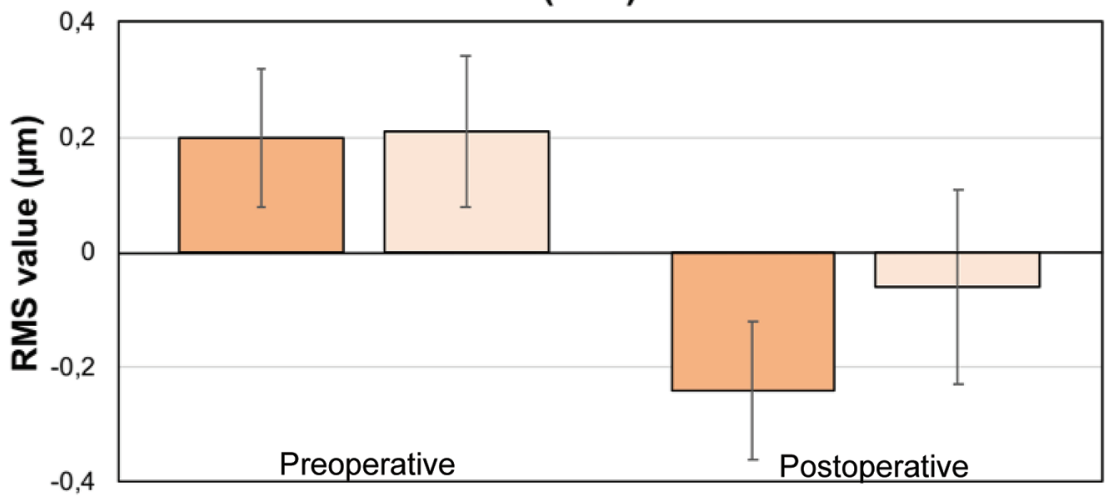

口NDE Corneal C4,0@6.0mm rDE Corneal C4,0@6.0mm

Change in Zernike corneal spherical aberration coefficient M12 - preop $(\Delta C 40)$

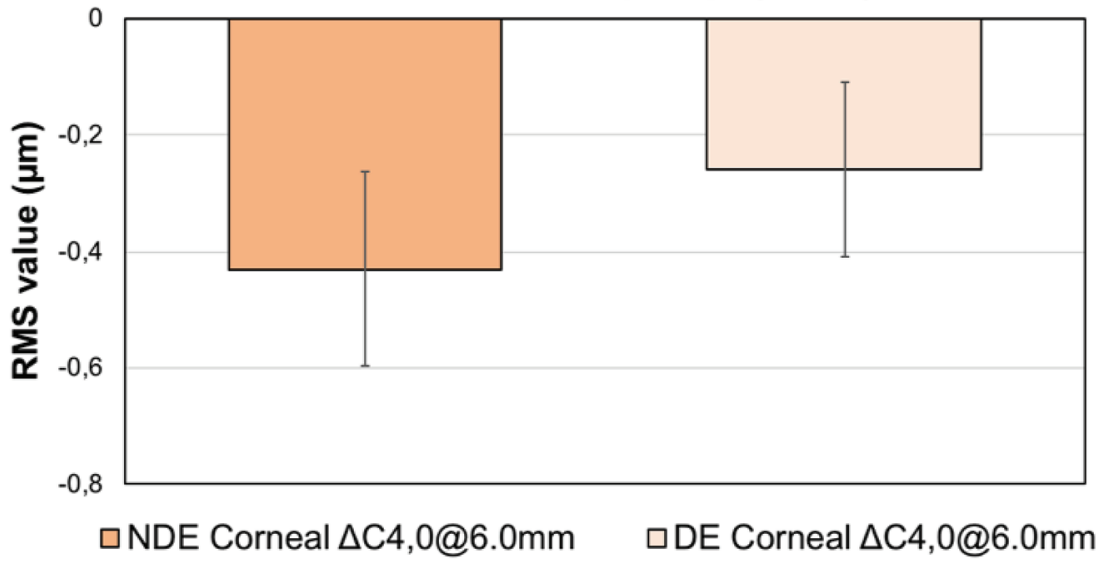


Spherical equivalent refraction stability of dominant eye

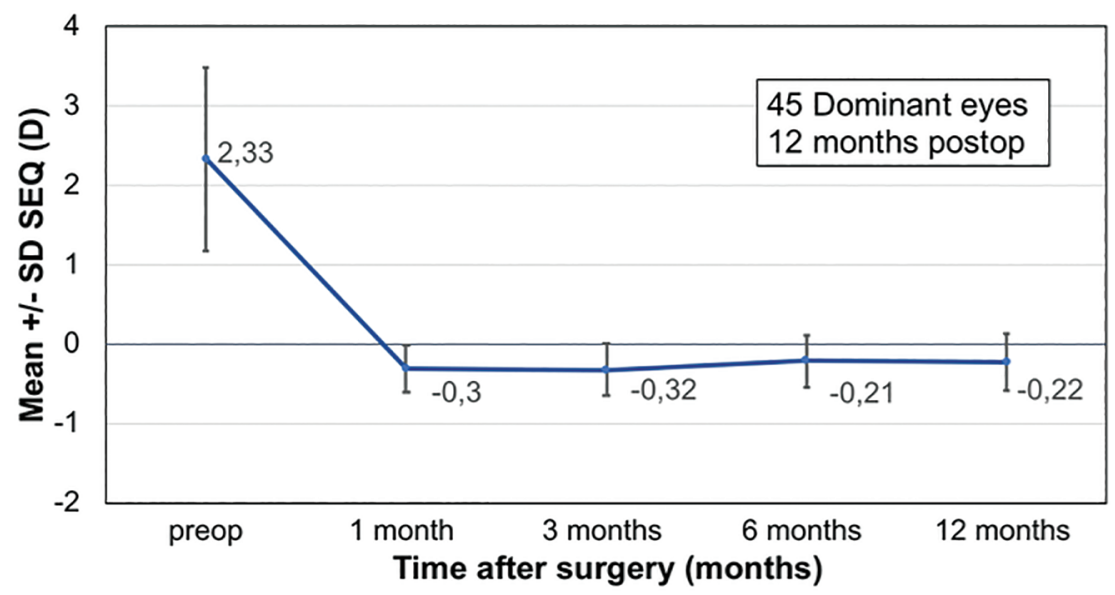

Spherical equivalent refraction stability of non-dominant eye

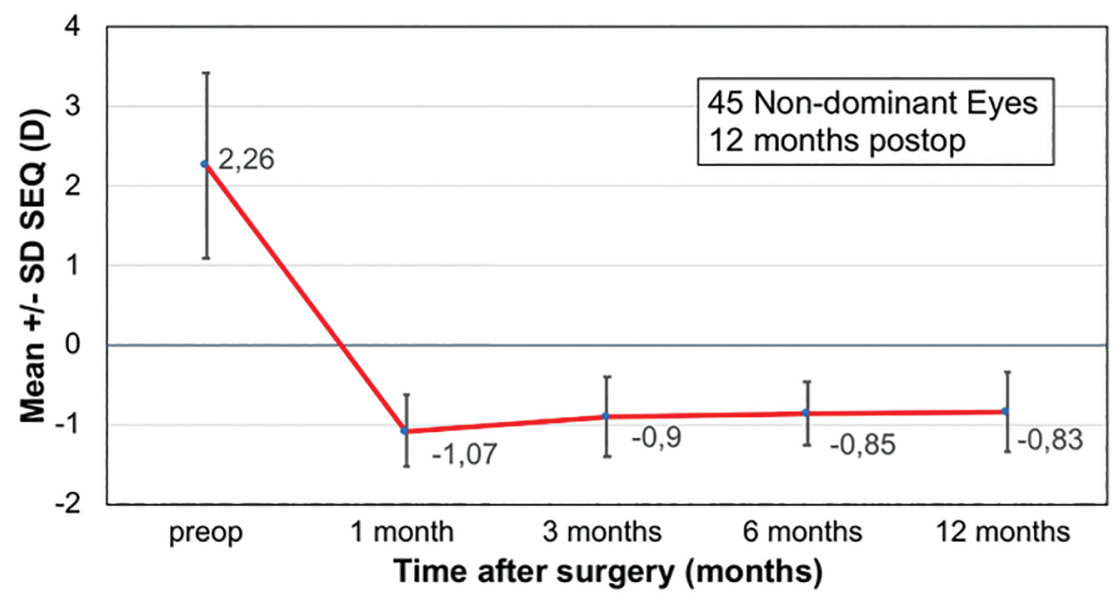




\section{5 eyes (Non-dominant eye) 1 year postop}

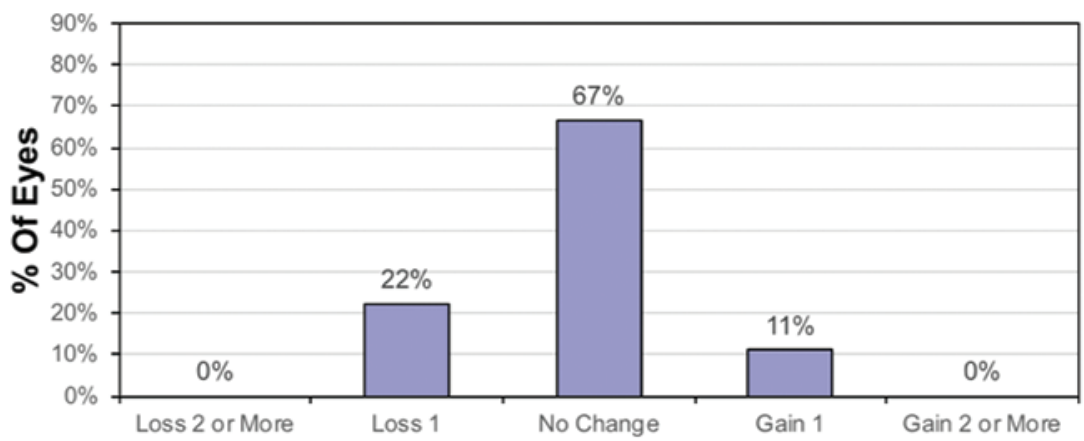

Change in Snellen lines of CDVA
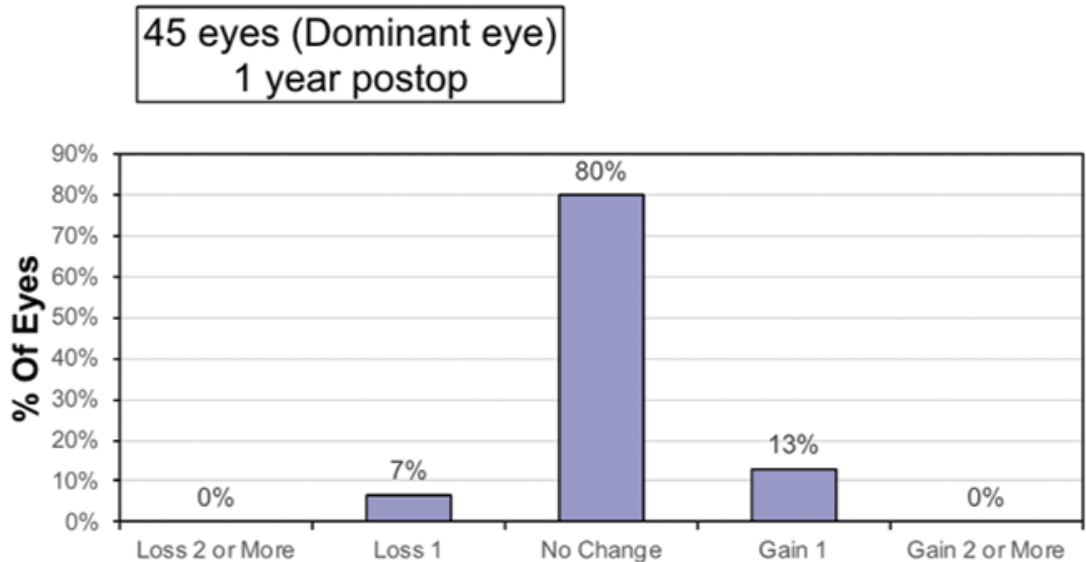

Change in Snellen lines of CDVA 


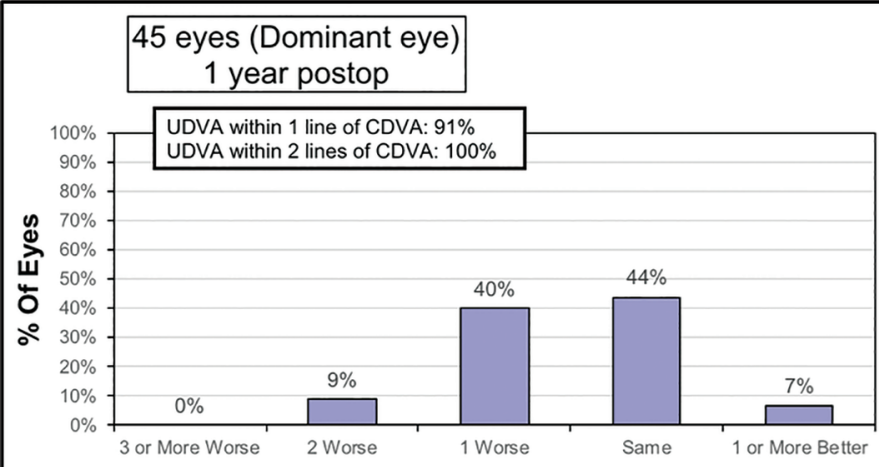

Difference between UDVA postop and CDVA preop (Snellen Lines)

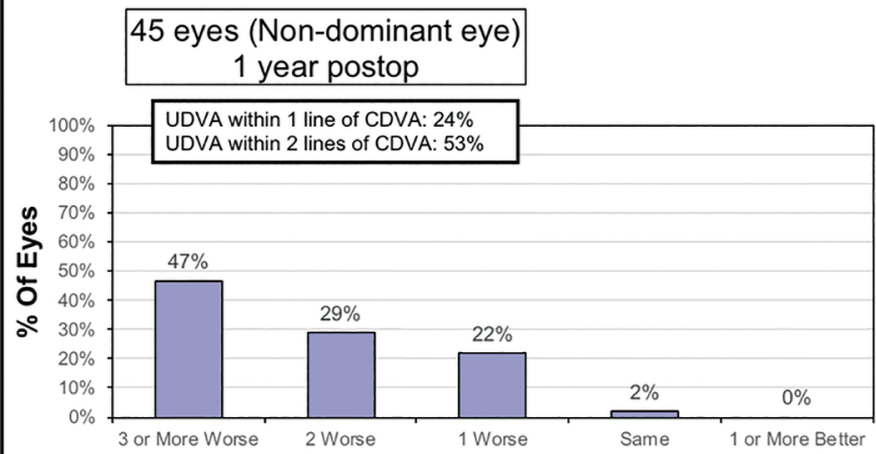

Difference between UDVA postop and CDVA preop (Snellen Lines)

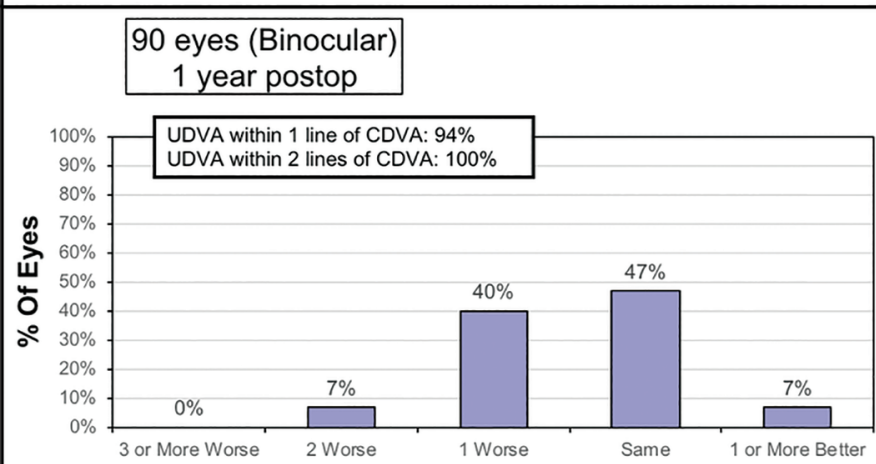

Difference between bilateral UDVA postop and CDVA preop (Snellen lines) 


\begin{tabular}{|c|c|c|c|c|}
\hline & \multicolumn{2}{|c|}{ Preoperative data } & \multicolumn{2}{|c|}{1 year after surgery } \\
\hline Age (years) & \multicolumn{4}{|c|}{$53.8 \pm 4.99$ years } \\
\hline \multirow[t]{3}{*}{$\operatorname{Sex}(M / F)$} & \multicolumn{4}{|c|}{$20 / 25$} \\
\hline & Dominant eyes & Non Dominant eyes & Dominant eyes & Non dominant eyes \\
\hline & $\begin{array}{c}\text { Mean } \pm \mathrm{SD} \\
\quad \text { (range) }\end{array}$ & $\begin{array}{c}\text { Mean } \pm \text { SD } \\
\quad \text { (range })\end{array}$ & $\underset{(\text { range })}{\operatorname{Mean}} \pm$ SD $(P$ value $)$ & 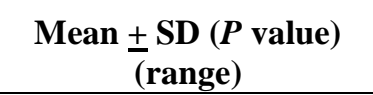 \\
\hline Sphere (D) & $\begin{array}{c}+2.47 \pm 1.17 \\
(+1 \text { to }+6)\end{array}$ & $\begin{array}{l}+2.43 \pm 1.14 \\
(+1 \text { to }+5.5)\end{array}$ & $\begin{array}{c}-0.022 \pm 0.32(P<0.0001) \\
(-0.75 \text { to }+0.75)\end{array}$ & $\begin{array}{c}-0.58 \pm 0.54(P<0.0001) \\
(-1.5 \text { to }+0.75)\end{array}$ \\
\hline Cylinder (D) & $\begin{array}{c}-0.33 \pm 0.35 \\
(-1.5 \text { to } 0)\end{array}$ & $\begin{array}{c}-0.36 \pm 0.34 \\
(-1.5 \text { to } 0)\end{array}$ & $\begin{array}{c}-0.40 \pm 0.25(P=0.22) \\
(-1.25 \text { to } 0)\end{array}$ & $\begin{array}{c}-0.53 \pm 0.24(P=0.013) \\
(-1.25 \text { to } 0)\end{array}$ \\
\hline $\begin{array}{c}\text { Spherical } \\
\text { equivalent (D) }\end{array}$ & $\begin{array}{l}+2.33 \pm 1.16 \\
(+0.75 \text { to }+6)\end{array}$ & $\begin{array}{c}+2.26 \pm 1.17 \\
(+0.25 \text { to }+5.5)\end{array}$ & $\begin{array}{c}-0.22 \pm 0.35(P<0.0001) \\
(-1 \text { to }+0.5)\end{array}$ & $\begin{array}{c}-0.83 \pm 0.50(P<0.0001) \\
(-1.875 \text { to }+0.375)\end{array}$ \\
\hline $\begin{array}{c}\text { Minimal } \\
\text { pachymetry }(\mu \mathrm{m})\end{array}$ & $\begin{array}{c}541 \pm 30 \\
(500 \text { to } 600)\end{array}$ & $\begin{array}{c}539 \pm 30 \\
(500 \text { to } 602)\end{array}$ & $\begin{array}{c}522 \pm 24(P<0.0001) \\
(480 \text { to } 575)\end{array}$ & $\begin{array}{c}524 \pm 28(P<0.0001) \\
(474 \text { to } 589)\end{array}$ \\
\hline Kmax (D) & $\begin{array}{c}44.3 \pm 1.47 \\
(40.7 \text { to } 47.1)\end{array}$ & $\begin{array}{c}44.1 \pm 1.45 \\
(40.5 \text { to } 47.6)\end{array}$ & $\begin{array}{c}45.3 \pm 1.29(P=0.0002) \\
(43.1 \text { to } 47.7)\end{array}$ & $\begin{array}{c}45.5 \pm 1.37(P<0.0001) \\
(42.7 \text { to } 48.4)\end{array}$ \\
\hline Q-factor at $6 \mathrm{~mm}$ & $\begin{array}{c}-0.18 \pm 0.04 \\
(-0.27 \text { to }-0.11)\end{array}$ & $\begin{array}{l}-0.19 \pm 0.05 \\
(-0.28 \text { to }-0.1)\end{array}$ & $\begin{array}{c}-0.48 \pm 0.03(P<0.0001) \\
(-0.74 \text { to }-0.42)\end{array}$ & $\begin{array}{c}-0.78 \pm 0.04(P<0.0001) \\
(-0.88 \text { to }-0.69)\end{array}$ \\
\hline $\begin{array}{c}\text { Corneal spherical } \\
\text { aberration } \mathrm{C}_{4}{ }^{0} \text { at } \\
6 \mathrm{~mm}(\mu \mathrm{m})\end{array}$ & $\begin{array}{c}0.21 \pm 0.13 \\
(0.01 \text { to } 0.38)\end{array}$ & $\begin{array}{c}0.20 \pm 0.12 \\
(0.01 \text { to } 0.34)\end{array}$ & $\begin{array}{c}-0.06 \pm 0.17(P<0.0001) \\
(-0.34 \text { to }+0.16)\end{array}$ & $\begin{array}{c}-0.24 \pm 0.12(P<0.0001) \\
(-0.45 \text { to }-0.05)\end{array}$ \\
\hline $\begin{array}{c}\text { Mean UDVA } \\
(\operatorname{logMAR})\end{array}$ & $\begin{array}{l}0.45 \pm 0.28 \\
(-0.1 \text { to } 1)\end{array}$ & $\begin{array}{l}0.45 \pm 0.29 \\
(0 \text { to } 1)\end{array}$ & $\begin{array}{c}-0.068+0.07(P<0.0001) \\
-(-0.2 \text { to }+0.1)\end{array}$ & $\begin{array}{c}0,29 \pm 0.17(P=0.0003) \\
(0 \text { to } 0.6)\end{array}$ \\
\hline $\begin{array}{c}\text { Mean CDVA } \\
(\operatorname{logMAR})\end{array}$ & $\begin{array}{c}-0.084 \pm 0.076 \\
(-0.2 \text { to } 0)\end{array}$ & $\begin{array}{c}-0.098 \pm 0.076 \\
(-0.2 \text { to } 0)\end{array}$ & $\begin{array}{c}-0.092 \pm 0.06(P=0.796) \\
(-0.2 \text { to } 0)\end{array}$ & $\begin{array}{c}-0.091+0.067(P=0.405) \\
(-0.2 \text { to } 0)\end{array}$ \\
\hline
\end{tabular}

Table 1: Ocular characteristics of the 45 patients at inclusion and 1 year after surgery. $M$ : male; F: female; SD: standard deviation; D: diopters; UDVA: uncorrected distance visual acuity; CDVA: corrected distance visual acuity; CNVA: corrected near visual acuity. $t$-test for paired data (comparison of postoperative and preoperative values; $P<0.5$ indicates significance). 